\title{
"A FIJAR CON RITMO Y RIMA / EL FLUYENTE PENSAMIENTO»: HUELLAS DEL CANCIONERO MEDIEVAL EN EL CANCIONERO DE UNAMUNO
}

\author{
Norbert von Prellwitz \\ Sapienza, Università di Roma
}

Pensar en una relación entre la poesía cancioneril castellana y el Cancionero póstumo (1953) de Miguel de Unamuno parecería sensato, considerando que después de haber dedicado dos libros al soneto -Rosario de sonetos líricos (1911) y De Fuerteventura a París (1925)- el libro de poesía sucesivo, Romancero del destierro (1927), señalaba una línea evolutiva de interés en las formas anteriores al soneto -aunque de hecho el empleo del romance en sentido estricto se limite a la breve sección final del libro- interés retrospectivo que el título Cancionero parece confirmar.

Sin embargo, ya el máximo experto del Cancionero unamuniano, Josse De Kock, señalaba en su imprescindible Introducción al Cancionero de Miguel de Unamuno ${ }^{1}$ que hay que distinguir dos momentos en la formación de la obra: un primer período constituye la continuación del Romancero en lo que se refiere a enfoques dominantes, aunque el uso asiduo del octosílabo implique cambios expresivos; lo demuestra el hecho que durante el otoño de 1928 Unamuno escribiese un prólogo al que entonces se llamaba aún Cancionero del destierro, título evidentemente paralelo al del libro anterior ${ }^{2}$.

1929 es un año fecundo para el Cancionero (más de 900 textos añadidos a los casi 600 del primer proyecto «del destierro»), y aunque siga habiendo variedad métrica, el esquema de base dominante es la cuarteta de octosílabos, lo que, unido a una menor incidencia de notas cotidianas en verso -cuyo conjunto, además del orden estrictamente cronológico, debió inducir a Federico de Onís a añadir el subtítulo Diario poético en su edición póstuma del

${ }^{1}$ Josse de Kock, Introducción al Cancionero de Miguel de Unamuno, Madrid, Gredos, 1968.

${ }^{2}$ Ibidem, pp. 20 y ss. La mención del Canzoniere de Petrarca por parte del poeta portorriqueño José Agustín Balseiro parece haber sido decisiva en el proyecto del Cancionero unamuniano, empero sin ningún intento de componer un conjunto orgánico como el del poeta italiano. 
Cancionero unamuniano, la primera ${ }^{3}$ - permite deducir un cambio de orientación en la poética implícita del libro. Es precisamente sobre la base de la producción poética a partir de 1929 que Josse de Cock desarrolla su interpretación del papel que asume el modelo ya dominante de la cuarteta tradicional en el Cancionero de Unamuno. Como dicha interpretación se desarrolla en varios pasos de su Introducción (que incluye varios estudios), me permito reunir las observaciones de Kock en un conjunto más compacto, que resume la recapitulación expuesta en el capítulo «La versificación»"

a. Las composiciones no forman conjunto entre sí; son independientes (aunque, añado yo, hay algunas series en ciertas fechas y variaciones frecuentes sobre un mismo tema a lo largo del libro);

b. El verso predominante a lo largo del Cancionero es el octosílabo: 974 poemas usan este metro, 58 de los cuales incluyen también el pie quebrado.

c. La inmensa mayoría de los poemas (las nueve décimas partes del Cancionero) tienen un número total de versos múltiplo de 4 o de 3 ;

d. Los esquemas de rimas confirman este reparto: abab en 634 poemas; abba en 276 , aabb en 15 ;

e. Al principio Unamuno emplea casi exclusivamente la rima asonante, que va disminuyendo paulatinamente hasta desaparecer por completo a partir del poema 770, un año después de los primeros versos. [...] El número de los poemas aconsonantados alcanza el 100 por 100 de las composiciones en otoño de 1929 (n. $\left.{ }^{\circ} 1200-1300\right)$. [...] Hay 1376 poemas aconsonantados, 350 asonantados y 46 en versos blancos.

Kock interpreta certeramente tales datos como prueba de una decisión innovadora del escritor respecto a esquemas formales anteriores:

Este estado de cosas constituye una revolución dentro de la obra poética de Unamuno. En los treinta años que don Miguel escribió poesía, tan solo una vez había recurrido al octosílabo de una manera asidua: al final del Romancero del destierro, terminado en 1927, ni siquiera un año antes de comenzar el Cancionero. Más aún, en 1919 todavía Unamuno lo rechazaba explícitamente, prefiriendo la métrica de la silva [...]. Ahora bien, precisamente a expensas del endecasílabo, empleado tan abundantemente en las combinaciones más variadas en todos los libros de poesía anteriores al Cancionero, Unamuno entroniza el octosílabo 5 .

${ }^{3}$ Miguel de Unamuno, Cancionero. Diario poético, Buenos Aires, Losada, 1953. Sobre la cuestión véase Kock, Introducción, ob. cit., p. 60.

${ }^{4}$ Ibídem, pp. 78-109.

${ }^{5}$ Ibídem, pp. 84-85. 
Esta conclusión abría en aquel entonces el camino a estudios circunstanciados sobre las formas expresivas del Cancionero, cosa a la que Kock, hecha la salvedad de algunos aspectos retóricos, no se dedicó en el libro, limitándose a sentar las bases para un desarrollo amplio como demuestra la expectativa escrita en 1962 que cierra su «Introducción»: «Creemos que estos estudios [...] pueden parcialmente facilitar la lectura y el estudio del cancionero, pero deben sobre todo [...] servir de punto de partida para otros estudios más detallados $[\ldots]\rangle^{6}$. Sin embargo, a juzgar por la bibliografia al respecto, el deseo de Kock ha tenido poco eco.

Quien hojee los tomos pertinentes de Historia y crítica de la literatura española esperando encontrar un buen número de estudios sobre el Cancionero unamuniano, se lleva un chasco, a pesar de que, como afirma José-Carlos Mainer en su perfil bibliográfico de 1980, «nos hallamos ante alguno de los máximos logros poéticos de Unamuno y precisamente en razón de aquella componente de repentización (sobre un recuerdo nimio, una impresión fonética, un trivial episodio doméstico y a menudo tan frustrada por sus glosas filosóficas)» ${ }^{7}$. De hecho Mainer debe limitarse a señalar el trabajo de Josse de Kock, aunque vale la pena mencionar un par de páginas dedicadas al Cancionero por Francisco Ynduráin (la fecha de publicación original del texto es 1969), a propósito del uso de la rima: anota el estudioso que «nos encontramos con la marcada intensificación del empleo de rimas perfectas», y destaca la función "generadora que lleva de la palabra a la idea»"

Aparentemente algo ha cambiado antes de 1994, si en el tomo de puesta al dia de Historia y crítica Mainer observa que el Cancionero «se lleva la parte esencial de la bibliografía sobre la lírica unamuniana: varios trabajos asedian su indiscutible componente de diario de las inquietudes filosóficas, religiosas y políticas [...], otros analizan la presencia del tema de España [...], unos terceros ensanchan el conocimiento de su estructura $»^{9}$. De hecho basta una mano para contar las contribuciones, y el único estudioso que ha empleado una perspectiva más estrictamente literaria es - ¡vaya sorpresa!- Josse de Kock ${ }^{10}$. Asimismo es muy escueta la bibliografía de estudios que figura en la edición del Cancionero cuidada por Ricardo Senabre: 11 títulos $^{11}$.

\footnotetext{
${ }^{6}$ Ibidem, p. 195.

${ }^{7}$ Francisco Rico (dir.), Historia y crítica de la literatura española, t. 6: Modernismo y 98, ed. José-Carlos Mainer, Barcelona, Crítica, 1980, p. 244.

${ }^{8}$ Ibidem, p. 387.

${ }^{9}$ Ibidem, p. 228.

${ }^{10}$ Josse de Kock, «Géometrie et poésie dans Cancionero de Miguel de Unamuno», Les Lettres Romanes, 41 (1987), pp. 235-244.

${ }^{11}$ Ricardo Senabre, «Introducción», en Miguel de Unamuno, Obras completas, ed. de Ricardo Se-
} 
Es decir que las observaciones de Kock de 1968 en los preliminares de su «Introducción»: «el Cancionero es una de las obras de Unamuno peor conocidas», y «cuando se viene a tratar del Cancionero es, en general, en función de uno de los grandes temas de la obra unamuniana», lamentando la ausencia de trabajos estilísticos, siguen -sorprendentemente- teniendo vigencia.

Probablemente incide mucho sobre esta situación la masa de poemas (1765 según el cómputo de Kock), y la evidente desigualdad de nivel, que en repetidas ocasiones se debe, como observó Mainer, a un lastre de explicitación del pensamiento ya expresado por la organización retórica y por las imágenes iniciales del poema afectado; podríamos decir con un término cancioneril que se trata de un exceso de glosa, procedimiento que sin duda es la base de muchos de los poemas del libro. Como demuestra en algunos ejemplos Kock, Unamuno no publica todo lo que escribe, pero sí publica mucho, con el criterio de no elegir entre los poemas que considera terminados, considerados todos hijos espirituales y expresión de sus vivencias. Por lo tanto el investigador obstinado debe tener el interés y la paciencia de seleccionar, sin olvidar que textos menos logrados pueden ser complemento de (e incluso ilustrar) los de calidad mayor.

Algunas de las expansiones en perspectiva estilística y lingüística las ha llevado a cabo el mismo Kock: además del estudio señalado por Mainer, otros artículos entre 1969 y 1987 se hallan recogidos en el segundo libro publicado en 2006 sobre el Cancionero, que constituye la puesta al día de su meritoria investigación sobre esta obra de Unamuno ${ }^{12}$ con la intención de «examinar ese marco, organización o estructura, que constituye el hecho poético y la originalidad de Cancionero, [...] dejando a un lado los temas desarrollados $\rangle^{13}$.

Ya que Kock no se ha ocupado de manera específica en sus estudios de la dialéctica entre las formas expresivas tradicionales adoptadas por el poeta en su Cancionero y los modos y resultados de la aplicación de esas formas -que en buena parte se pueden definir de tipo cancioneril-en manos de un poeta anticonformista y muchas veces innovador, me propongo realizar aquí unos sondeos iniciales en esa dirección.

Uno de los ejemplos que aporta Kock para mostrar el desarrollo de un poema del Cancionero es el poema n. ${ }^{\circ} 1001$ (04.04.1929), del que ilustra cuatro versiones ${ }^{14}$. A partir de un apunte en el que es evidente la función

nabre, tomo V: Cancionero, Poesías sueltas, Traducciones, Madrid, Fundación José Antonio de Castro, 2002, pp. XIX-XX.

${ }^{12}$ Josse de Kock, Cancionero de Miguel de Unamuno, Salamanca, Universidad de Salamanca, 2006. Véanse sobre todo las partes III, IV y v.

${ }^{13}$ Ibidem, p. 16.

${ }^{14}$ Kock, Introducción, ob. cit., pp. 44-46. 
generadora de la rima -ya presente en los borradores del Rosario de sonetos líricos (1911) como referencia frecuente- ${ }^{15}$, para componer una cuarteta monorrima:

La alcachofa es una estrofa fofa de pobre estofa cofa como de mofa en cada verso todo cofa. gofa, ruda, torpe gallofa

que parece casi una parodia de textos vanguardistas, mientras otra cuarteta sigue el modelo más tradicional de una redondilla:

Tres décimas rimbombantes

Bernardo López García

ya no son plato del día

si es que lo hayan sido antes.

Podríamos considerarla una copla de escarnio de las que gastaban los poetas medievales; el poeta aquí denostado, muy apreciado en el siglo precedente, es el representante de un tipo de poesía que Unamuno aborrece, también por razones de ritmo, si recordamos el «sonsonete melopeico y bastante metronómico y primitivo» que caracteriza en su opinión la versificación de Zorrilla ${ }^{16}$.

Ahora bien; como observa Kock, el poeta percibe analogías entre los dos textos y trata de combinarlos. Omito las tentativas, para las que remito a Kock, para presentar de manera más sorpresiva el resultado final, que es una quintilla dominada por figuras fónicas, sin ninguna referencia ya a la cuarteta satírica:

Pela de hojas la alcachofa
versos son de fofa estrofa,
leyenda de gofa estofa,
jerga de mofa la cofa
y en el garrucho gallofa.

Además de las rimas que han determinado el desarrollo del texto, con eco de doble repique en los versos 2, 3 y 4, noto las asonancias iniciales de los vv. 1, 3 y 4, aliteraciones y paronomasia: en definitiva Unamuno eligió

\footnotetext{
${ }^{15}$ Véanse también los ejemplos que aduce Kock, Cancionero, ob. cit., pp. 16-17.

${ }^{16}$ Véase «El zorrillismo estético» (1917). Cito por Miguel de Unamuno, Obras completas, ed. de Manuel García Blanco, t. III: Nuevos ensayos, Madrid, Escelicer, 1968, p. 1001.
} 
redondear un monstruo sonoro, exaltando «el valor corporal de la palabra por sí, del sonido», como observa en el prólogo de 1928 destinado a la primera versión del Cancionero ${ }^{17}$. Una idea cabal del tipo de actividad mental que podemos imaginarnos como motivación profunda de este lúdico poema $\mathrm{n}^{\circ}{ }^{\circ}$ 1001 (4.08.1929) es la analogía que el autor añade a continuación: «Se dice de algún escultor que llevaba siempre consigo una pellita de barro de modelar hiñiéndola entre sus dedos».

A parte la metáfora del barro modelado que remite a la creación del hombre por parte de Dios, y es por lo tanto imagen de la creatividad, el símil con la escultura recuerda que «de escultor y no sastre es tu tarea» según reza el primer «Credo poético» unamuniano $(1907$, v. 14$)$ y al mismo tiempo remite a la dimensión de molde que tiene la copla rimada, lo que explica el valor que esta forma tradicional ha adquirido en los últimos años del quehacer poético de Unamuno, como resume perfectamente el poema metapoético n. ${ }^{\circ} 1254$ :

Cubo de dos: ocho, y rima

que del cubo haga cristal

y a la palabra redima

de su barro natural. (13.09.1929, p. 1284)

Al mismo tiempo este molde evita el ritmo monótono de tamboril zorrillesco a través de un ritmo variado, que vemos ilustrado tempranamente en otro metapoema, el n. ${ }^{\circ} 102$ :

... Se escapa a saltos el canguro; fluye

ondulante serpiente entre la yerba.

Ritmo pedís? De salto en el desierto;

de deslices malignos en la selva. (10.4.1928, p. 982)

Dejo al lector el gusto de apreciar los juegos fónicos en estos endecasílabos asonantados para comentar que los dos polos rítmicos, salto y fluidez, expresan la preferencia por un ritmo poético complejo, enunciada en varias ocasiones por Unamuno, como en la crítica del zorrillismo sonoro: «La

\footnotetext{
${ }^{17}$ Unamuno, Obras completas, ed. cit., t. VI: Poesía. En lo sucesivo las citas del Cancionero se refieren a esta edición, con la advertencia que Kock critica el hecho de que García Blanco haya intervenido sistemáticamente en la división en estrofas de poemas cuyo texto manuscrito no las presenta, y normalizando la puntuación - con la excepción de los signos exclamativos e interrogativos inicialeshabitualmente escasa en los manuscritos. Pude observar un proceder análogo en el caso de los sonetos: véase Norbert von Prellwitz, «Le edizioni dei sonetti di Unamuno e la volontà dell'autore», en Ecdotica e testi ispanici, Università di Padova, Facoltà di Economia e Commercio - Istituto di Lingue e letterature straniere, Verona, 1982, pp. 125-134.
} 
melodía de Zorrilla es melodía de caramillo de pastor. A lo más, de flauta. Al órgano apenas llega, y a la orquestación nunca» ${ }^{18}$. Ello implica que también la cuarteta tradicional de octosilábos se vea sometida a esta dinámica, por lo menos como ideal realizado en los poemas más logrados, lo que conlleva una tensión respecto a las figuras reiterativas, animando así el esquema cúbico de base como acaece en la construcción asimétrica del poema ${ }^{\circ}{ }^{\circ} 1720$, que cierra el conjunto de la poesía escrita en 1934:
La figura es hondura, el sonido es sentido; hundirse en visión, sentirse en el son. (p. 1412)

Aunque con un menor exceso reiterativo en la orquestación sintáctica comparado con «Pela de hojas la alcachofa», la redondilla del poema $\mathrm{n}^{\circ}$ 1429 muestra que los procedimientos de cristalización en el molde de la estrofa tradicional pueden también producir resultados de eficaz estilización (el ejemplo me sugiere la denominación de haiku cancioneril):

\author{
La brisa briza a la rosa \\ mientras que toca la Musa \\ del aire su cornamusa \\ y danza la mariposa. (11.1.1930, p. 1324)
}

Eficaz complemento de la más sencilla copla $n .^{\circ} 125$, ya aconsonantada:

Son vuelos entre flores

sueños de mariposa, arrullos de colores, inquietud que reposa. (18.4.1928, p. 988)

Hay en el Cancionero varios poemas que remiten directamente al modelo cancioneril; un ejemplo evidente es el muy esmerado poema $n .^{\circ} 808$, que glosa la desgarradora imagen de la separación entre los dos cónyuges presentada en el v. 375 del Cantar de mio $\mathrm{Cid}^{19}$; sus rasgos expresivos subrayan la dedicatoria a D. Ramón Menéndez Pidal:

\footnotetext{
${ }^{18}$ Unamuno, «El zorrillismo estético», art. cit., p. 1002.

${ }^{19}$ Véase el comentario al episodio en «Doña Ximena»: Unamuno, Obras completas, ed. cit., t. III, p. 1026.
} 
Como de la carne uña se parte de su Rodrigo su Jimena;

la querencia los apuña; el salirse de su abrigo recia pena.

Los brazos del Caballero le tiemblan estremecidos del querer; tiemblan las aguas del Duero y le ahogan los gemidos al nacer.

Se le clavan en los ojos los ojos que son su vida por venir; le llegan los recuerdos rojos el agüero no se olvida al partir.

Ya se sale el Caballero, ya deja en paz a su tierra reposar; las altas aguas del Duero, desde el Urbión, brava sierra, van al mar. (8.3.1929, pp. 1184-1183)

Unamuno substituye al romance -demasiado obvio para el tema cidiano (pero la anáfora de «Ya» recuerda lo ausente)- la copla de pie quebrado, que constituye un homenaje implícito a uno de los poetas más apreciados por él (baste como muestra el epígrafe de Manrique que abre el capítulo final de Vida de Don Quijote y Sancho, además de varias alusiones en el mismo), y sería suficiente el último verso para alertar al lector distraído. No falta una dosis de romanticismo (que corresponde a la equivalencia propuesta por Unamuno en el comentario de un romance viejo: «las nubes de romance, las nubes románticas», equivalencia subrayada por el juego etimológico ${ }^{20}$ ) y abundan por supuesto varias especias unamúnicas, componiendo casi un menú postmoderno.

${ }^{20}$ Miguel de Unamuno, «Las coplas de Calaínos», en íd., Obras completas, ed. cit., t. III, p. 1008. 
Desde luego los estudiosos más expertos que yo en poesía cancioneril y en cancioneros populares hallarán muchas más huellas de adaptación de modelos tradicionales en el amplio repertorio del Cancionero unamuniano, y a ello les aliento. Pero no quiero pasar por alto otro aspecto de la cuestión: también presenta tema y tonos medievales el malicioso poema $n .^{\circ} 699$ en el que el juego etimológico y la paronomasia, tan frecuentes en la poesía cancioneril medieval, llevan la voz cantante:

Por el camino de Roma

que iba siguiendo a mal tino

rindió la sed al romero,

al romero peregrino;

vio en una puerta una rama, rama arrancadas a un espino,

y pidió agua a la ramera

que en vez de agua le dio vino.

La ramera y el romero

comulgaron de camino

Roma y rama es casi rima,

el casi: agorero sino!:

romería y ramería

casan ya en común destino. (14.02.1929, p. 1157)

Omito aquí las relaciones de consecutividad con el poema n. ${ }^{\circ} 698$, que es un diálogo en verso entre los mismos personajes, pero con un final bastante flojo, y la incidencia de los epígrafes de William Blake en la interpretación de ambos textos.

Pero sí resulta oportuno citar aquí la esclarecedora consideración sobre los artificios retóricos activos tanto en este poema como en los citados anteriormente, tal como la expusiera Unamuno en el prólogo del año precedente a propósito de «cosas de más forma aún, de la formalidad de la forma»:

Las palabras mismas suscitan ideas. El que cría palabras o asiste con amor a su crianza, las ahíja, las hace hijas suyas. La etimología amorosa es una fuente de poesía, de re-creación, de anapoesía, de palimpoesía. Los llamados aciertos poéticos suelen ser aciertos verbales. Hay tal juego de palabras que es juego de conceptos, conceptismo y juego de pasión. Porque las palabras levantan pasiones y emociones; y acciones (p. 944). 
Lo compacto de la cuarteta tradicional, dinamizada en su interior por los cruces e interferencias de juegos fónicos y retóricos, se presta en los casos más eficaces a conferir un realce particular a la expresión de sentencias, aforismos y refranes que constituyen una parte importante del Cancionero. Véase por ejemplo el poema n. ${ }^{\circ} 1283$, de aire muy tradicional y al mismo tiempo tan machadiano, que expresa como consecuencia del compás uniforme la consiguiente longevidad del poema en la memoria de sus oyentes y lectores:

Corazón, a metro late,

ni te salgas del compás, ni la prisa te arrebate,

porque así descansarás.

Marcha a paso de andadura

vera del río, verás

cómo viene la ventura

y deja al sueño detrás.

Marcha a latidos contados

y a brisa, del verde a ras,

$\mathrm{y}$ en versos acompasados

senda larga gozarás. $(8.10 .1929$, p. 1291)

En polémica contra el concepto de moda de «poesía pura», Unamuno defiende en el prólogo antes mencionado su propio concepto de poesía pura, que es en definitiva crear lenguaje:

Y acaso la más honda finalidad de la poesía literaria, de la creación por lenguaje hablado y escrito, es crear lenguaje. [...] Los giros, dichos, refranes con que piensan $-\mathrm{y}$ sienten- los más, se los deben a poetas, a creadores, de la mayoría de los cuales se han olvidado los nombres (p. 945).

Otro ejemplo: la glosa unamuniana no declarada como tal de la paradoja «que muero porque no muero» apunta con un guiño final a una inversión del sentido religioso más corriente en el poema $n .^{\circ} 1380$ :

Me muero porque te quiero

y es querer un puro engaño;

te quiero porque me muero

y es morir todo mi apaño. $(8.12 .1929$, p. 1312) 
Podemos interpretar «apaño» según la primera acepción que nos indica Autoridades: «En el sentido recto vale agarro, retención, ocupación», aunque el mismo diccionario nos advierta: «pero en él tiene mui poco uso y se toma regularmente por disposición, industria, ò modo para poder hacer y obrar», y si se nos ocurre sospechar a lo picaresco del término «industria», llegaremos a leer la cuarteta a lo profano, como hubiera hecho Keith Whinnom con un poema amatorio medieval; es suficiente leer en el Diccionario de uso del español de María Moliner que el sentido menos recto pasa por «arreglo de cualquier asunto hecho sin escrúpulo», sinónimo de «amaño», hasta llegar a «amancebamiento».

Que tal interpretación no sea irreverente ni improbable lo demuestra el hecho que existe en el Cancionero una veta de sensualidad y erotismo -como ya vimos en el poema n. $^{\circ} 699$ - que casi permitiría componer un pequeño cancionero de burlas. Me limito a otros tres ejemplos:

\author{
La dama Doña Marcolfa, \\ señora de Don Bertoldo, \\ fue a convertir a una golfa. \\ que ejercía bajo un toldo; \\ pero ésta la puso en solfa \\ atizándole el rescoldo. (27.3.1929, p. 1220)
}

Venus te valga! Qué grupa! no es de mujer, es de yegua de parada; si te ocupa cuitado, no tendrás tregua. $(13.11 .1929$, p. 1299)

La estatua oyendo al través suspiros de una pareja se dice para su reja: «qué es lo que vendrá después?» (21.11.1929, p. 1303)

Al fin y al cabo el alter ego del nivolista Unamuno, Víctor Goti, dedica tres párrafos en el prólogo de Niebla al «consorcio de lo erótico con lo metafísico», concluyendo: «Y si todo esto no es así como digo, no se me negará al menos que es ingenioso, y basta $\aleph^{21}$.

Si cabe reprochar algo a Josse de Kock, es que su imagen del escritor Unamuno mantiene un perfil demasiado serio y severo: «difícilmente imaginamos

${ }^{21}$ Ver Unamuno, Obras completas, ed. cit., t. II: Novelas, pp. 547-548. 
a Unamuno distrayéndose gratuitamente» ${ }^{22}$. Puede discutirse lo de «gratuitamente», si tenemos en cuenta el metapoema invocatorio n. $^{\circ} 964$ :

\author{
Ajo de Aristófanes ático, \\ otórgame, Apolo, \\ y logre vivir en abismático \\ reírme más solo; \\ todo es problemático $(27.3 .1979$, p. 1220)
}

Pero creo que dentro de la «vitalidad desbordante» ${ }^{23}$ que Kock reconoce en las modalidades expresivas dominantes en el Cancionero, existe un gusto de lo lúdico que en parte no escasa del libro remite a las vanguardias: que Unamuno, siempre reacio a dejarse llevar por la corriente, recobre la experiencia de las vanguardias, algunas de ellas a destiempo, no debería sorprendernos.

Ricardo Senabre observa que «no cabe desdeñar esta intensa búsqueda de la experimentación verbal, paralela a los numerosos patrones retóricos que Unamuno ensaya en los poemas del Cancionero, que van desde simples anáforas y paralelismos hasta artificios más complejos, como los quiasmos y las anadiplosis» ${ }^{24}$.

La paradoja es que sus experimentos se ven exaltados por el marco estricto de la copla tradicional. La base del procedimiento reside en la superposición e intersección semántica incrementada por la densidad fónica. La forma más simple es, por ejemplo, el siguiente pareado en el que Unamuno emplea una de sus formas predilectas de generación cognitiva, el quiasmo:

Jugar con fuego: lucir la cruz;

foguear el juego: cruzar la luz. (2.3.1929, p. 1173)

La elaboración retórica confiere espesor semántico a esta instantánea neoeglógica y a su manera neogongorina:

Lampazo aterrado al suelo, en torno trébol tirita y virginal margarita abre párpados al cielo (27.3. 1929, p. 1220)

${ }^{22}$ Kock, Introducción, ob. cit., p. 154.

${ }^{23}$ Ibídem, p. 191.

${ }^{24}$ Senabre, «Introducción», en Miguel de Unamuno, Obras completas, ed.. cit., t. V, p. XIV. 
De la misma fecha -rica de hallazgos, puesto que presenta trece poemases esta fábula, glosa del conocido versículo del evangelio de Mateo, virado irónicamente hacia una actitud de paciencia digna de Job:

Por el ojo de un camello pasa una aguja y le deja tuerto: el camello se aleja encorvado triste el cuello, pero no se queja. (p. 1220)

Mientras es autoirónica o expresión de momentáneo desaliento respecto a la labor del diario poético que es el Cancionero, esta otra fábula-glosa:

Ardilla de devaneos,

la hojarasca al nogal meces,

$\mathrm{y}$ al fin de tantos rodeos

mucho ruido y pocas nueces. (18.12.1929, p. 1315)

Como observa Ricardo Senabre, «hay secuencias lógicas que parecen surgir de sucesivas conmutaciones fonológicas ${ }^{25}$, aportando como ejemplo significativo el poema $n .^{\circ} 756$ :

Pisos de alfombra, visos de sombra;

lechos de rosas, techo de losas, hechos y cosas. $(2.3 .1929$, p. 1172)

El procedimiento compositivo no difiere básicamente del que observamos en el poema 1001 («Pelas de hoja la alcachofa») citado arriba, aunque aquél pueda definirse en su extremosidad una parodia dadaísta (como fue dadaísta el Unamuno que lanzaba pajaritas de papel sobre los colegas parlamentarios); entre los primeros poemas escritos a su vuelta a España Unamuno incluso inventa una fórmula combinatoria, no menos vanguardista, para explicar el método:

Por lógica y aritmética

al obtener $n$ ritmos

tomas de textos de estética,

la tabla de logaritmos. (25.3.1930, p. 1329)

${ }^{25}$ Ibidem, p. XIII. 
La idea de fondo es análoga a la que subyace a la selección combinatoria con la que Juan Ramón Jiménez aspiraba a alcanzar el nombre exacto de las cosas. Dos estrofas del poema n. ${ }^{\circ} 394$ de Unamuno -muy didascálico, pero valga como declaración pertinente-, apuntan hacia un horizonte común de desnudez poética:

\author{
¿Pretendes desentrañar \\ las cosas? Pues desentraña \\ las palabras, que el nombrar \\ es del existir la entraña. \\ $[\ldots]$ \\ Si aciertas a Dios a darle \\ su nombre propio, le harás \\ Dios de veras, $\mathrm{y}$ al crearle \\ tú mismo te crearás. (11-12.9.1928, p. 1074)
}

No cabe duda que si Unamuno acompaña muy a tiempo el redescubrimiento de la poesía tradicional por los poetas del ' 27 , sus escarceos vanguardísticos no dejan de tener interés, y se han lanzado como sugerencia de afinidades la poesía juvenil de Gerardo Diego, de José Bergamín, de Valle Inclán, sin dejar de mentar la greguería de Ramón Gómez de la Serna. Valdría la pena explorar en ese sentido las numerosas coplas aforísticas y sentenciosas en las que Unamuno compite a distancia con su amigo Antonio Machado, o también imágenes singulares como la perífrasis de la amapola en «Corazón negro con alas / de fuego y presas a tierra» (n. ${ }^{\circ} 206,8.6 .1928$, vv. 1-2, p. 1012).

Por ello disiento de la opinión de Josse de Kock cuando interpreta la vigencia de la estrofa tradicional en el Cancionero como la solución para llegar «a hacer del poema un todo acabado, cerrado y equilibrado», ya que, a la luz de mi experiencia de lector, tengo mis reservas sobre los adjetivos que Kock emplea, pero sobre todo no creo que Unamuno lo hiciera en función antivanguardista. Afirma Kock:

La poesía unamuniana se destaca así de las composiciones voluntariamente caóticas, tan a menudo favoritas de sus contemporáneos superrealistas. Puede que no sea pura coincidencia el hecho de que, como el octosílabo, el paralelismo sea una forma típica de la tradición española ${ }^{26}$.

\footnotetext{
${ }^{26}$ Kock, Introducción, ob. cit., p. 188.
} 
Ante todo el único vanguardista que Unamuno cita en el prólogo provisional del Cancionero es el futurista Marinetti, a propósito de atrevimientos formales que tilda de convencionales: «Las famosas palabras en libertad de Marinetti no son palabras», concluye Unamuno defendiendo su propia vuelta a las formas métricas tradicionales. No nos sorprende, ya que Guillermo de Torre, quien en Hélices consiguiera imitar perfectamente a Marinetti, más tarde renegó de él en su Historia de las literaturas de vanguardia. Será por poner en solfa esa pretendida libertad que Unamuno la enjaula en una copla todavía asonantada con visos futuristas antes de escribir ese prólogo:

Volando cantan hélices de acero; ya viene el tiempo del robusto encanto; graznan los cisnes al morirse o callan; se baña en nubes rígido aeroplano. (10.4.1928, p. 982)

Por otra parte, los superrealistas que tuve ocasión de estudiar -Alberti, Aleixandre, García Lorca- no tienen absolutamente nada de caótico; requieren una lectura adecuada a la compenetración de varios planos semánticos. Si Kock explica que en el Cancionero el «poema se compone a menudo de enfoques repetidos de un mismo asunto, mediante un mismo o distintos procedimientos. Unamuno no prosigue el desarrollo sistemático de un tema; vuelve siempre a tomarlo desde su principio. No hay extensión del tema, sino redoblamiento ${ }^{27}$, podríamos interpretar este recurso como la aplicación literaria de un principio artístico, el del cubismo sintético, que representa varios planos del objeto en la misma obra, aun sin forzar la identificación de la forma métrica como un cubo cristalizado por la rima que vimos en el poema n. ${ }^{\circ} 1254$ citado arriba. El paso ulterior es la dinamización de los planos por medio de la densidad retórica -a veces excesiva, como se ha visto- que multiplica la constelación de interpretaciones. En este sentido interpreto el metapoema ${ }^{\circ}{ }^{\circ}$ 1654 no como la imagen de un poema cerrado, sino como la condensación de lo múltiple: el universo en la célula sonora de la cuarteta rimada:
A fijar con ritmo y rima
el fluyente pensamiento
y bien contorneado a lima
a darle firme cimiento.
A sujetar todo el coro
de la humanidad al verso

${ }^{27}$ Ibidem, pp. 186-187. 
y en un átomo sonoro

a encerrar el universo. (5.8.1934, p. 1392)

Cuando Unamuno lo logra, cumple la gran hazaña de transformar formas de ascendencia medieval en poesía modernísima.

Recibido: 26/06/2014

Aceptado: 30/09/2014

\section{$\cos$}

«A FIJAR CON RITMO Y RIMA / EL FLUYENTE PENSAMIENTO»:

HUELLAS DEL CANCIONERO MEDIEVAL EN EL CANCIONERO DE UNAMUNO

Resumen: La adopción de la cuarteta aconsontada y de otras formas tradicionales de tipo cancioneril en el Cancionero de Unamuno tiene una función sobre todo condensadora y rítmica, presentando varios aspectos: desde formas imitativas e híbridas que incluyen temas medievales, pasando por aforismos y sentencias, hasta experimentos de tipo vanguardístico que multiplican planos semánticos.

Palabras clave: Unamuno. Cancionero. Estrofa tradicional. Poesía medieval. Poesía del siglo $x \mathrm{x}$.

\section{«A FIJAR CON RITMO Y RIMA / EL FLUYENTE PENSAMIENTO»: Footprints of Medieval CANCIONERo in UnAmuno’s CANCIONERo}

ABSTRACT: The adoption of the rhymed quartet and of other traditional medieval Spanish poetry patterns in Unamuno's Cancionero has mainly a condensing and rhythmic function, offering different aspects, from hybrid counterfeits which include medieval themes, going through aphorisms and sayings up to avant-garde experiments which multiply semantic layers.

KeYwords: Unamuno. Cancionero. Traditional strophe. Medieval poetry. $20^{\text {th }}$ century poetry. 